\title{
CHRONIC DISSECTING ANEURYSMS
}

\author{
BY \\ A. MORGAN JONES AND F. A. LANGLEY \\ From the Cardiographic Department, Manchester Royal Infirmary, and the Department of Pathology, University \\ of Manchester \\ Received May 20, 1946
}

In 1939 East was able to find records of only 27 instances in which the diagnosis of dissecting aneurysm had been made during life. Usually death from complete rupture of the aorta quickly follows the initial dissection; of the 300 cases collected by Shennan (1934) 210 died within a week and survival for more than a year was recorded in only 16 cases. We have, therefore, thought it desirable to record two cases in which the diagnosis was made during life; one patient survived for three years and the other is alive and comparatively well eight years after radiographic recognition of the aortic lesion.

\section{CASE RECORDS}

Case 1. In December 1943, a married woman, aged 55, was admitted to the Manchester Royal Infirmary under the care of Dr. Crighton Bramwell, on account of severe pain in the back of the chest and in the lumbar area. Apart from an attack of smallpox when 4 and an operation for uterine prolapse when 41, she enjoyed good health until the age of 52 years. She was then suddenly seized by severe stabbing pain in the left anterior chest which radiated to the left scapular region and the dorso-lumbar area. She fell to the ground but did not lose consciousness. She was confined to bed for two weeks and suffered from some aching pain in the left chest for four or five weeks. Subsequently she remained well for nearly a year, when a similar attack took place; her blood pressure was then found to be 230/130. Following this attack her pain again gradually disappeared and she remained in comparatively good health for a year, when her third attack of severe pain occurred. She was admitted to hospital and the heart and aorta were found to be enlarged radiographically. On this occasion, however, her pain did not subsequently disappear, but extended to the lumbar area. After several months of persistent pain in the chest and back she was admitted to the Manchester Royal Infirmary in April 1943, under the care of Dr. Oliver. Her blood pressure was then $210 / 135$ in the right arm and 195/130 in the left. Cardioscopy showed gross dilatation of the aorta. The Wassermann reaction was negative and a diagnosis of chronic dissecting aneurysm was made. She remained in bed for four months; but was never free from pain. When she got up, walking 20 yards brought on severe anginal pain; this gradually improved, but in November 1943 she began to suffer from attacks of palpitation of sudden onset, lasting several hours. She was readmitted under the care of Dr. Bramwell. Her blood pressure was then $225 / 140$ in the left arm and 210/140 in the right. On cardioscopy the aorta was grossly dilated and the left ventricle enlarged (Fig. 1 and 2). The blood Wassermann and Kahn reactions were negative. A cardiogram showed left axis deviation and biphasic $\mathrm{T}$ waves $(-+)$ in leads I and II, with depression of the corresponding RS-T segments; these appearances were attributed to left ventricular strain associated with her hypertension. While in hospital she had several attacks of palpitation, during one of which a cardiogram showed paroxysmal auricular tachycardia at a rate of about 160 a minute. These attacks could be stopped at once by carotid sinus pressure, but the ectopic rhythm was re-established a few minutes after pressure was released. While in bed her pain diminished but did not altogether disappear. Some eight weeks after admission, and shortly before she was to go home, she collapsed in the lavatory and fell to the ground semi-conscious, with an imperceptible pulse. She improved slowly but complained of severe pain in the left chest; four days later she suddenly collapsed and died within a few minutes.

A necropsy was performed nine hours after death. Apart from slight passive congestion of the abdominal viscera, the abnormalities were confined to the thorax. The left pleural cavity was filled with straw-coloured fluid and blood clot; this had led to collapse of the left lung. 


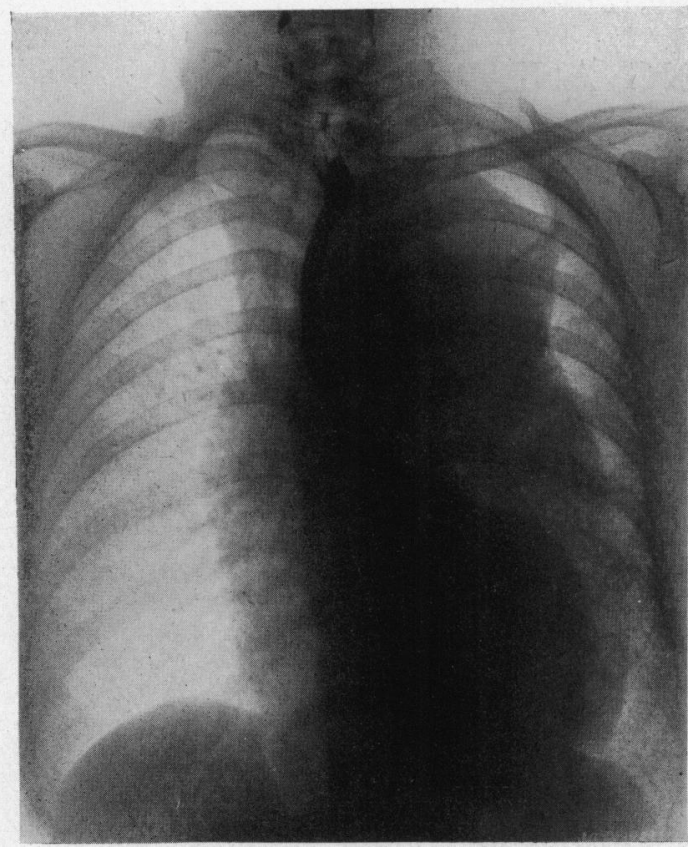

Fig. 1.-Case 1. Postero-anterior teleradiogram. The heart outline can be seen in front of the shadow of the greatly enlarged aorta.

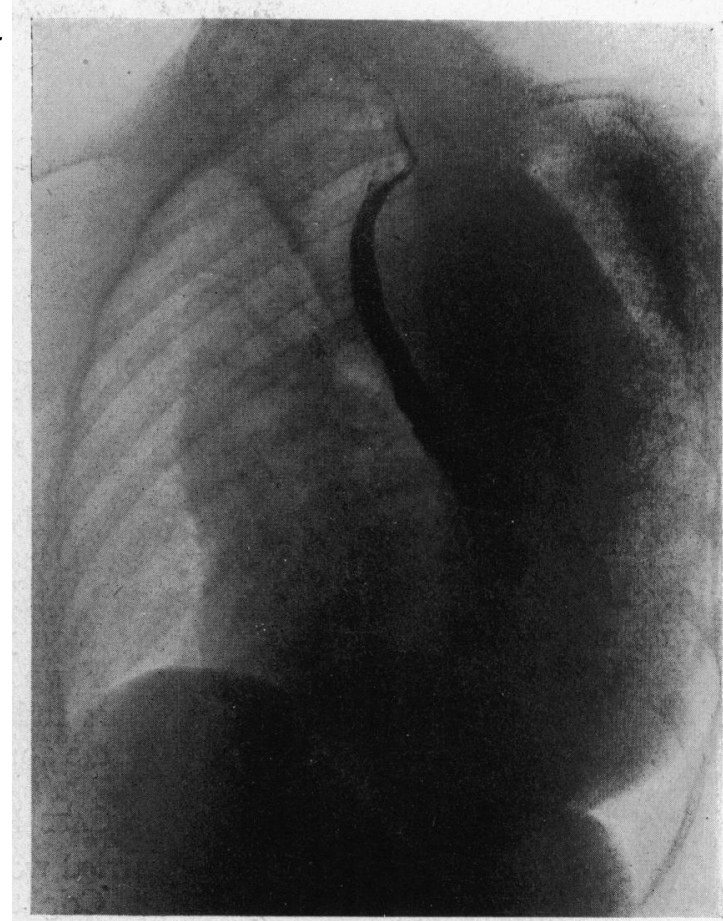

FIG. 2.-Case 1. Left anterior (II) oblique radiogram, showing the great size of the descending thoracic aorta. The aortic window is still visible for the ascending aorta is not greatly enlarged.

The heart weighed $390 \mathrm{~g}$., the left ventricle was hypertrophied but not dilated, and there were many pearly-grey areas of myocardial fibrosis. The right ventricle and all the valves were normal. The circumference of the aortic orifice was not increased $(6 \mathrm{~cm}$.). Numerous atheromatous plaques were present in both coronary arteries but the lumen was not severely narrowed at any point.

Externally the aorta was greatly dilated from just below the origin of the left subclavian artery to the level of the diaphragm (Fig. 3). At about the middle of the lateral surface of the dilated portion there was a transverse tear, $2 \mathrm{~cm}$. long, where the aneurysm had ruptured into the left pleura. On opening the aneurysm (Fig. 4) two channels were seen; on the inner border a narrow, flattened channel (A) led from the normal arch of the aorta to a dilated blind sac, in which the orifices of the last two pairs of aortic intercostals could be seen; this narrow channel was, therefore, the compressed descending thoracic aorta. The second channel (B) formed the greater part of the specimen and was continuous with the arch of the aorta above and with the abdominal aorta below. It was partially lined by laminated thrombus (C) and the external tear communicated with it. Where the two channels arose from the arch of the aorta the free edge of the septum separating them was rounded and smooth and continuous with a ridge around the mouth of the larger channel (Fig. 4, inset); the free margin had clearly been separated from this ridge when the dissection started and, since both ridge and free edge were smooth and healed, this separation was not recent.

Sections from the arch of the aorta, the walls of the aneurysm, and the abdominal aorta were stained with hæmalum and eosin, van Gieson, mucicarmine, Sudan IV, and Weigert's elastic stain. Sections from the aneurysm showed that at a and a' (Fig. 5, see p. 195) the media had split, two-thirds of its tissue passing inwards to cover the septum between the two channels and one-third lining the outer wall of the larger channel; the aneurysm had thus arisen by a separation of the outer third from the inner two-thirds of the media. Within the intima of the original aorta (A), at its acute angles (near a and $a^{\prime}$ ), there were polyhedral cells loaded with fat and between them large blood capillaries, while superficially a zone of young connective tissue and organizing blood clot invaded the original lumen of the aorta; in time this process could have obliterated the lumen of the compressed aorta. The lateral wall of the aneurysm was lined by dense fibrous tissue covered in some places by endothelium, in others by organizing thrombus. 


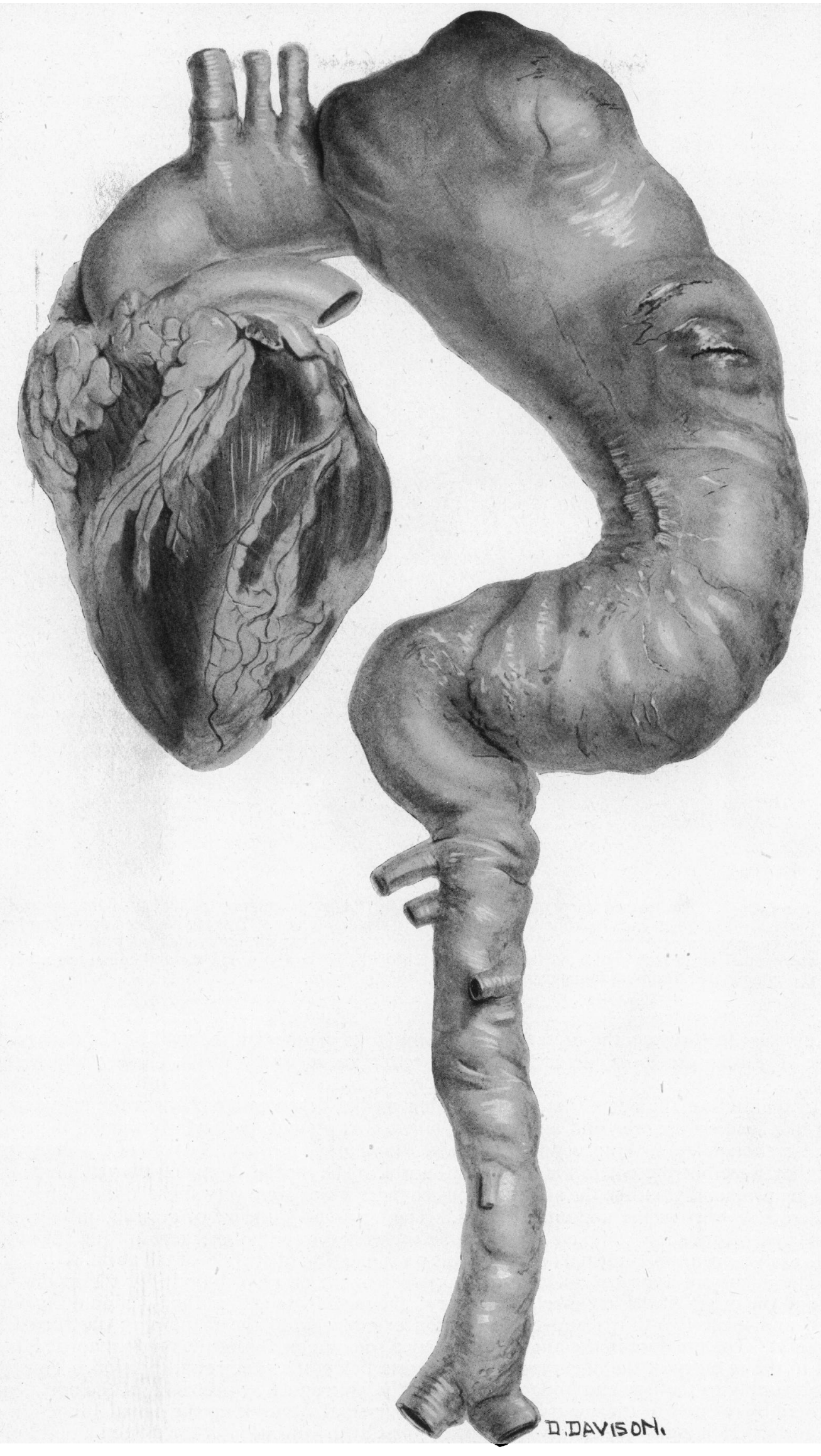

FIG. 3.-Case 1. The aneurysm from a water-colour painting. The transverse tear is visible on the left border of the aneurysm. The aneurysm does not extend below the diaphragm. The ascending aorta and the abdominal aorta are not enlarged. 
An unusual feature was the presence of atheromatous plaques on the wall of the aneurysm; these have been previously described in a dissecting aneurysm by Weiss, Kinney, and Maher (1940).

In the arch of the aorta there were striking medial degenerative changes for many small cyst-like spaces were seen and an excess of mucin was present, particularly around the cysts. Similar, though less striking, changes were also found in the media of the wall of the aneurysm, but they were not present in the abdominal aorta. The medial degeneration was thus most striking proximally, unlike the atheromatous changes which were very slight in the arch but of moderate severity in the abdominal aorta. There was no evidence of destruction of elastic tissue apart from a few complete breaks at the angles of the compressed aorta. The adventitia and vasa vasorum were normal and there was no suggestion of syphilis of the aorta.

The aneurysm appeared to have developed from the entry of blood into the media just beyond the origin of the left subclavian artery; the media was split at the junction of its outer third and inner two-thirds and the dissection extended until the diaphragm obstructed its advance. The pressure in the aneurysmal sac led to compression of the original aortic lumen and to the re-entry of the aneurysm into the aorta below the compressed portion. Thus the blood supply to the legs and abdomen, transiently interrupted by occlusion of the aorta, was restored by re-entry of the aneurysm and the aneurysmal sac took up the original function of the aorta. Healing of the aneurysm followed; first by organization of the clotted blood lining 
its walls, then by the development of a lining of endothelium. Finally, reparative processes began in the angles of the compressed aorta; this process, if continued, would have led to obliteration of the functionless lumen.

Case 2. In 1939, a single woman, aged 36 years, was admitted to the Manchester Royal Infirmary under the care of Dr: Crighton Bramwell, complaining of palpitation and breathlessness. Apart from measles as a child, she had been well until 1933, when she was a probationer nurse, aged 30 years. She then began to suffer from severe pain in the back which was treated by radiant heat and massage and disappeared after several months. In January 1938 she developed acute bronchitis; during this illness she awoke one night with a severe attack of palpitation and subsequently suffered from dyspnœa, palpitation, and lassitude. Some weeks later chest radiograms were taken and an enlarged substernal thyroid was diagnosed; she was treated with Lugol's iodine without benefit. In April 1938, while on sick leave in Ireland, she was admitted to hospital on account of her dyspnœa and palpitation. Her blood pressure was found to be 200/140 and radiograms of the chest showed moderate

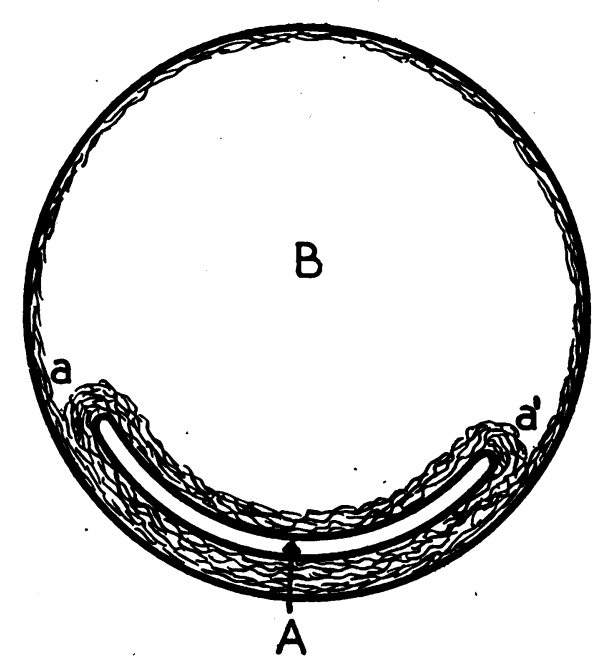

FIG. 5.-Case 1. Diagrammatic transverse section of the aneurysm. At $a$ and $a^{\prime}$ the media has split, one-third of its tissue lining the outer wall of the aneurysmal sac (B), and two-thirds covering the septum between the aneurysmal sac and the compressed lumen of the aorta (A). The aneurysm was, therefore, formed by splitting the media.

cardiac enlargement and considerable dilatation of the aorta. She was treated by X-ray therapy to the sternal area, but this was followed by intense pain in the back. While in hospital she had a uterine hæmorrhage and underwent a myomectomy for uterine fibroids; after operation she had periods of mental confusion and amnesia, and severe paroxysms of palpitation. In September, while trying to make her bed, she suddenly collapsed, and in December 1938, developed sudden severe dyspnœa with evidence of circulatory collapse. In March 1939 she returned to Manchester and remained in bed until she was admitted to hospital in May owing to. a severe attack of constricting chest pain which was followed by vomiting. Subsequently she had three similar attacks and in September developed acute bronchitis with hæmoptysis. A fifth attack of constricting chest pain followed this illness and in October 1939 she was admitted to the Manchester Royal Infirmary.

On examination the pulse rate was 120 and her brachial blood pressure 200/140; the same reading was obtained in the legs and there was good pulsation of the dorsalis pedis arteries. The heart sounds were very loud but no murmurs were present. Cardioscopy showed some enlargement of the left ventricle and considerable diffuse enlargement of the thoracic aorta (Fig. 6) with calcified plaques in its wall (Fig. 7). Kymography revealed quite good pulsation of the descending aorta. A cardiogram showed striking left axis deviation associated with biphasic T waves $(-+)$ in leads I and II and depression of the corresponding RS-T segments; these appearances ${ }^{4}$ were attributed to left ventricular strain associated with her hypertension. The blood Wassermann and Kahn reactions were negative and the urea clearance 75 per cent of the average normal. The condition was thought to be a chronic dissecting aneurysm.

While in hospital she suffered from severe aching pain in the left scapular region, headache, and palpitation. On several occasions she became confused and disorientated. Her condition had slightly improved when she left hospital in January 1940, but she continued to suffer from pain in the back and headaches until she was readmitted in December 1940, owing to the increasing severity of her pain and the onset of aching pain in the left leg. After her return home she remained in fair health, apart from the pain, until April 1941 when her right arm and leg became paralysed while she was out walking. The paralysis rapidly improved but some weakness of the right arm remained. In May she had a severe attack of sharp pain in the back of the chest, just to the left of the spine and in the left infra-scapular area. Subsequently she suffered from constant aching pain in this area with recurrent severe attacks of sharp pain, often precipitated by exertion. In August, severe aching pain developed in the epigastrium, and in November 1941 she was readmitted to hospital owing to the severity of her epigastric and chest pain. Her brachial blood pressure was then $165 / 110$ and the dorsalis pedis pressure 205/110. While in hospital she had two sudden severe attacks of 

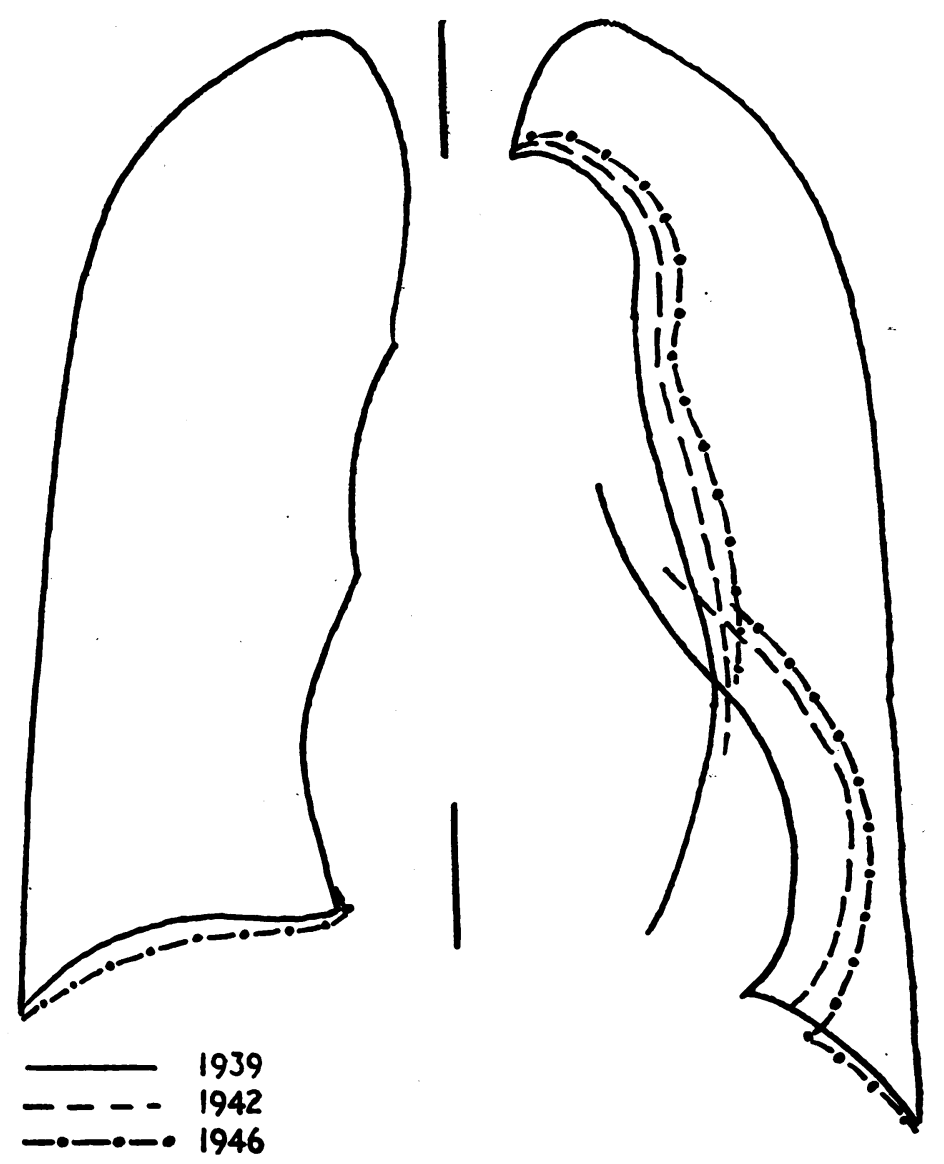

FIG. 6.-Case 2. Outline drawings from postero-anterior teleradiograms, 1939, 1942, and 1946 . The chest outlines were almost identical in all three radiograms and there has been little change in the contour on the right side of the cardiac silhouette. The gradual enlargement of the left ventricle and of the aorta is shown.

" grinding" pain in the left chest, relieved only by morphia, and followed by nausea and vomiting.

After her return home the pain continued to increase in severity and by March 1942 had become intolerable. When she was readmitted to hospital she complained of constant aching pain in the lower costal and lumbar region with several severe exacerbations each day, relieved only by morphia, and sudden attacks of constricting sternal pain, terrifying in character, but unrelated to exertion. The severity of these pains and the gradual deterioration in her condition demanded radical measures and paravertebral proctocaine injection of the upper 8 dorsal interspaces on both sides was attempted after a successful novocaine test. Unfortunately, the proctocaine injection failed to give much relief, and in August, Mr. Geoffrey Jefferson undertook paravertebral alcohol injection. After operation her pain remained severe for some weeks and she developed hyperæsthesia of the lower left thoracic root areas, fæcal and urinary incontinence, and pyramidal signs. Nevertheless, her pain gradually diminished and a year later, in August 1943, she was almost entirely free from pain and her neurological signs and symptoms had completely disappeared.

In 1944 she suffered from depression and was reluctant to get out of bed, but during the whole of 1945 she was active, undertook a great deal of housework and cooking and went to dances; she was entirely free from pain, gained weight, and lost all interest in her illness. In December 1945, however, cardioscopy showed some increase in the size of the heart and aorta and in the calcification of the aortic wall (Fig. 6, 7, and 8). Lateral and oblique radiograms of the thoracic spine did not show any erosion, the blood Wassermann reaction was negative, and the urea clearance 74 per cent of the average normal. It was noted that the right radial pulse was poorer than the left; the blood pressure in the right brachial artery was $200 / 125$, in the left $215 / 125$, and in the left dorsalis pedis artery $240 / 125$. 


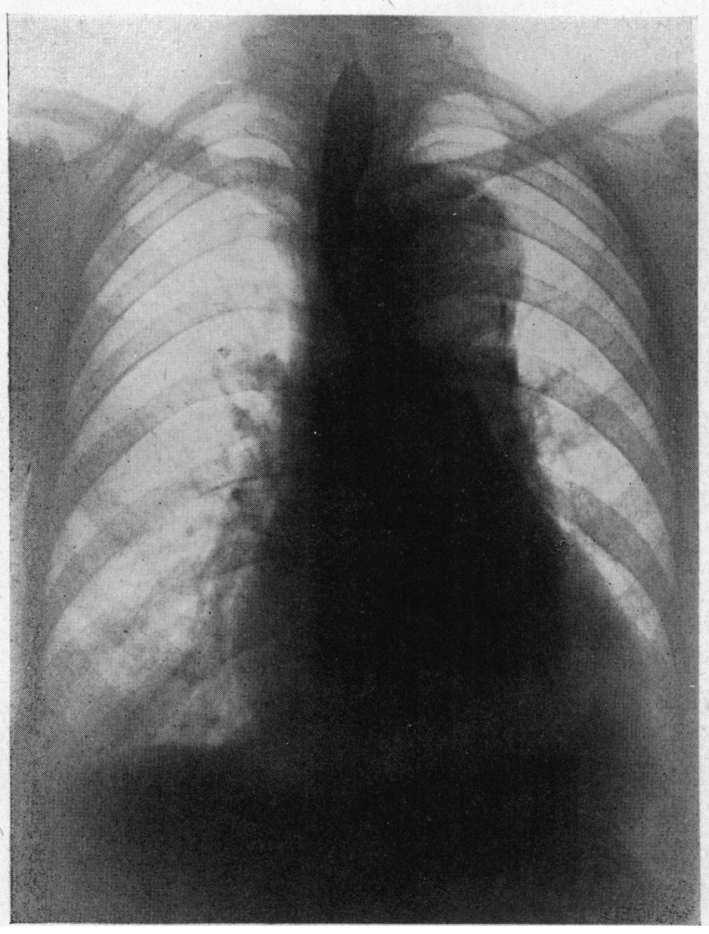

Fig. 7.-Case 2. Postero-anterior teleradiogram, December 1945. Calcification can be seen in the enlarged aortic knuckle.

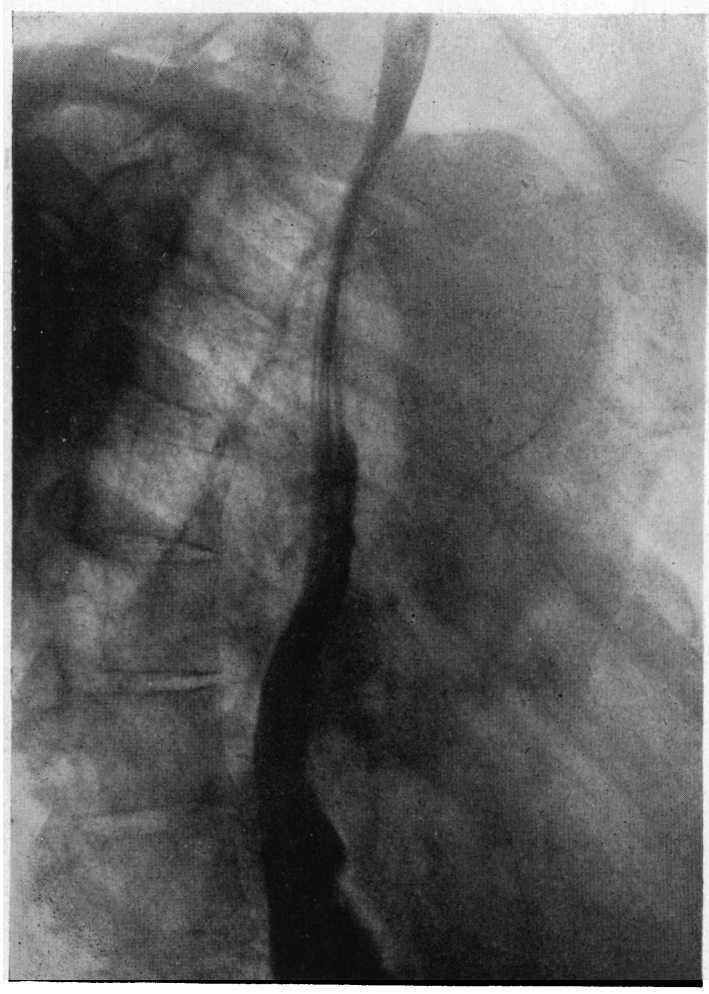

Fig. 8.-Case 2. Right anterior (I) oblique radiogram showing calcification of the enlarged aorta.

In January 1946 she was readmitted with acute bronchitis, from which she made an uneventful recovery.

\section{Discussion}

Virchow and other pathologists of his time thought that dissecting aneurysms arose from the dissection of blood through the floor or edge of an atheromatous ulcer. Subsequently this opinion was criticized by many pathologists and Shennan (1934) has reviewed the subject fully. In his own series Shennan found that only 6 of 218 recent dissecting aneurysms appeared to have started from an atheromatous ulcer: he emphasized the importance of medial degenerative changes, particularly those involving the elastic laminæ, and believed that the media nearly always gave way before the intima. Rottino (1939) studied the distribution of medial degenerative changes in 12 dissecting aneurysms and found that these changes were confined to the ascending and transverse aorta in 11 cases; this is probably significant for it is in these sites that the majority of dissecting aneurysms begin. Sailer (1942) studied and classified the types of medial degeneration that occur in the aorta. The histological appearances in our Case 1 are in general agreement with the views expressed by Shennan (1934) and Rottino (1939), and the degeneration is similar to that in certain of the types described by Sailer (1942).

Since survival for more than a few days is the exception when the aortic media is shattered by a sudden hæmorrhage, it is interesting to consider the factors that may avert death. Shennan (1934) found that death was due to external rupture in 195 (95 per cent) of 206 dissecting aneurysms that did not survive for more than a few days. If death is to be postponed it seems clear that some event must take place to make external rupture unlikely, and this can only be the relief of pressure in the aneurysmal sac. This happens when, as in Case 1, the aneurysm ruptures internally, so that the blood flow re-enters the original lumen of 
the aorta. The effect of re-entry on the period of survival is shown in Table I, which is compiled from Shennan's (1934) figures.

TABLE I

Effect of Re-entry on the Period of Survival

\begin{tabular}{l|c|c|c}
\hline & Number of cases & $\begin{array}{c}\text { Survival for less than } \\
5 \text { weeks }\end{array}$ & $\begin{array}{c}\text { Survival for more than } \\
5 \text { weeks }\end{array}$ \\
\hline $\begin{array}{l}\text { No re-entry } \\
\text { Re-entry }\end{array}$ & 199 & $192\left(\begin{array}{ll}(96 \%) \\
26 \quad(28 \%)\end{array}\right.$ & $\begin{array}{c}7 \\
66(4 \%) \\
(72 \%)\end{array}$ \\
\hline
\end{tabular}

Re-entry is, therefore, almost a pre-requisite of survival, for if it does not take place 96 per cent of patients die within five weeks, whereas when the circulation is re-established in this way only 28 per cent die in the first five weeks. Table I also shows that if the patient survives for more than five weeks, re-entry has taken place in 90 per cent (66 of 73 cases). This observation has an important bearing on the diagnosis of chronic dissecting aneurysm. In acute dissections East (1939) has emphasized the almost pathognomonic changes in the circulation of the legs due to obstruction of the aorta, which often afford convincing clinical evidence of the diagnosis. But when re-entry takes place the circulation is re-established in the legs; there will, therefore, be no evidence of aortic obstruction in 90 per cent of cases after the fifth week. Our Case 2 is an example of this, for the blood pressure in the legs was at least as high as that in the arms.

Shennan (1934) pointed out that re-entry into the original lumen is particularly liable to occur when the dissection reaches some obstruction, since this will increase the pressure in the aneurysmal sac. Mayr (1925) claimed that re-entrance usually took place into the iliac arteries, where the division of the aorta obstructs the progress of the dissection. The point of re-entrance was noted in 61 cases in Shennan's series; 43 aneurysms re-entered the pelvic branches of the aorta. Our Case 1 is an example of an unusual site of re-entry, for the extension of the aneurysm was prevented by the diaphragm and re-entry occurred at that level.

It was suggested by Bostrom (1888) that re-entry always prevented external rupture. This claim is not confirmed by our Case 1, and was criticized by Shennan for of 92 cases in his series in which re-entry ocqurred, external rupture also took place in 39 (42 per cent). On the other hand, when re-entry did not occur, external rupture took place in 95 per cent. Thus, although re-entry is no guarantee against external rupture, it does afford a considerable measure of protection against that fatal complication. Indeed, if re-entry takes place and the patient survives for more than a few weeks, there is a good chance that the aneurysm will not subsequently rupture. This is shown in Table II by an analysis of the causes of death in chronic dissecting aneurysms based on Shennan's (1934) figures.

TABLE II

Causes of Death in 79 Chronic Dissecting Aneurysms

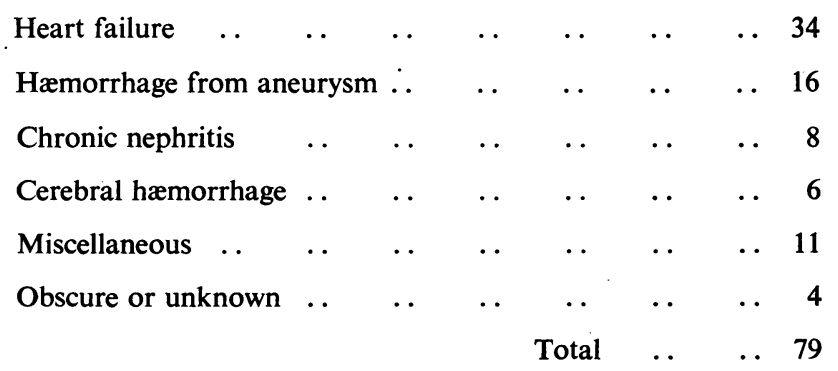

In our Case 2 there is, therefore, no reason to believe that the aneurysm must ultimately rupture, and survival has been recorded for more than 30 years (Graham, 1886). 
SUMMARY

Two cases of dissecting aneurysm, diagnosed during life and surviving in one case for three years and in the other for at least eight years, are described. The importance of re-entry in averting fatal rupture of the aneurysm is discussed, and its significance in the diagnosis of chronic dissecting aneurysm is indicated.

We are indebted to Professor Crighton Bramwell and to Professor S. L. Baker for their interest and advice and to Dr. E. Duff Gray for the radiograms. Professor Bramwell has kindly given permission to publish details of these cases, which were under his care.

\section{REFERENCES}

Bostrom, E. (1888). Disch. Arch. klin. Med., 42, 17.

East, T. (1939). Lancet, 2, 1017.

Graham, J. E. (1886). Amer. J. med. Sci., 91, 155.

Mayr, L. (1925). Z Zbl. Herz. Gefasskr., 17, 263.

Rottino, A. (1939). Arch. Path., 28, 377.

Sailer, S. (1942). Ibid., 33, 704.

Shennan, T. (1934). Spec. Rep. Ser., Med. Res. Counc., Lond., No. 193.

Weiss, S., Kinney, T., and Maher, M. (1940). Amer. J. med. Sci., 200, 192. 